\title{
EDITORIAL
}

\section{The systemic face of airway diseases: the role of C-reactive protein}

\author{
E.F.M. Wouters
}

$\Delta$ irway diseases, predominantly asthma and chronic obstructive pulmonary disease (COPD), are highly prevalent diseases, constituting a major financial burden to society. Both asthma and COPD are identified by the presence of characteristic symptoms and functional abnormalities. Airflow limitation is the dominant physiological characteristic of both diseases. The airflow limitation in asthma must be reversible to establish a diagnosis, whereas in COPD the airflow limitation does not change markedly over periods of several months and the disease is characterised by a steady downhill course over time. Asthma usually commences in childhood, whereas COPD is generally diagnosed at an older age. Lung inflammation induced by different initiating factors is now recognised as an important characteristic in both diseases. The airway inflammation in asthma is characterised by an increase in eosinophils, lymphocytes (predominantly of the CD4+ type) and mast cells. In contrast, inflammation in COPD can be described by a predominance of lymphocytes, in particular CD8+ lymphocytes, and large numbers of neutrophils in the airway lumen.

While achievement of asthma control and suppression of airway inflammation are considered as important management goals in asthma, particularly as a consequence of the effects of inhaled steroids in this disease process, the focus of research in COPD has moved from the typical pulmonary pathology of COPD to the role of numerous abnormalities outside the lung. At present, COPD is considered as a multicomponent disease, including skeletal muscle dysfunction and cachexia, as well as cardiovascular and osteoskeletal alterations. Particularly in order to explain the process of muscle wasting, the presence of a chronic low-grade systemic inflammatory response has been identified as one of the catabolic factors, although the precise role, as well as the intracellular pathways, remain to be defined [1]. In this issue of the European Respiratory Journal (ERJ), two clinical papers focus attention on the role of systemic inflammation, assessed by C-reactive protein (CRP), not only in COPD but also in asthmatic patients. DE TORRES et al. [2] have found that CRP levels are elevated in clinically stable COPD patients and that CRP levels correlate best with arterial oxygen tension and 6-min walking distance (6MWD). Furthermore, factorial analysis showed that CRP and corticosteroid use were identified as a separate dimension in this study population. In a smaller study, TAKEMURA et al. [3] have reported that elevated

CORRESPONDENCE: E.F.M. Wouters, Dept of Respiratory Medicine, University Hospital Maastricht, Maastricht, The Netherlands. Fax: 31 433875051. E-mail: e.wouters@lung.azm.nl
CRP is negatively associated with indices of pulmonary function and positively associated with sputum eosinophilia in steroid-naive asthmatics, but not in those treated with steroids.

The data of DE TORRES et al. [2] are confirmed by a large body of data that shows that systemic inflammation exists in stable COPD and that this systemic inflammation is related to functional performance. In a recent study, YENDE et al. [4] analysed data from elderly participants in the Health Aging and Body Composition study. They found that obstructive lung disease in this cohort was associated with lower quadriceps strength and higher interleukin (IL)- 6 and CRP levels. In the same study, higher systemic IL-6 and tumour necrosis factor levels were associated with a lower quadriceps strength and the IL-6 level was found to be an independent predictor of exercise tolerance. BROEKHUIZEN et al. [5] built on the observations by YENDE et al. [4] and reported that raised CRP levels in COPD patients admitted for pulmonary rehabilitation were associated not only with diminished muscle strength, but also with reduced exercise endurance, work load, 6MWD, increased resting energy expenditure and health status. PINTO-PLATA et al. [6] reported that 6MWD, age and body mass index (BMI) significantly predicted CRP levels in patients with COPD; the most important clinically relevant predictor was $6 \mathrm{MWD}$, which decreased with increasing CRP levels. Further studies are needed to investigate if systemic inflammation can be ascribed to muscle dysfunction and to unravel the role of muscle dysfunction itself in the process of systemic inflammation. Previously, IL-6 was identified as an "exercise factor", acting as an energy sensor in response to exercise and being produced by contracting muscle when glycogen content is low and subsequently released into the blood [7]. CRP production by hepatocytes is principally induced by IL-6. The relationship between systemic inflammation (in particular raised CRP levels) and functional performance has not been studied in asthmatic patients.

It is important to consider the differences in CRP levels between asthmatics and COPD patients, as is clearly illustrated by the data from both papers in this issue of the $E R J[2,3]$. The CRP levels in the study by DE TORRES et al. [2] are quite similar to data reported previously $[5,6]$, whereas the data from TAKEMURA et al. [3] fit very well with observations from previous studies in asthmatic patients $[8,9]$. Limited data are available about the prevalence of increased CRP levels in asthma and COPD. The prevalence of increased CRP in COPD patients has been examined in the National Health and 
Nutrition Examination Survey III where it was found that $41 \%$ of patients with moderate COPD (forced expiratory volume in one second (FEV1) $>50-80 \%$ predicted) had a CRP level $>3 \mathrm{mg} \cdot \mathrm{L}^{-1}$ and $6 \%$ had a level of $>10 \mathrm{mg} \cdot \mathrm{L}^{-1}$, whereas $52 \%$ of patients with severe COPD (FEV $1<50 \%$ predicted) had a CRP level of $>3 \mathrm{mg} \cdot \mathrm{L}^{-1}$ and $23 \%$ had a level of $>10 \mathrm{mg} \cdot \mathrm{L}^{-1}$ [10]. Further studies are urgently needed to assess the prevalence of increased CRP in well-defined COPD and asthma cohorts.

In cardiovascular literature, CRP is a marker of inflammation that predicts incident myocardial infarction, stroke, peripheral arterial disease and sudden cardiac death among healthy individuals with no history of cardiovascular disease, and recurrent events and death in patients with acute or stable coronary syndromes [11].

CRP levels of $<1,1-3$ and $>3 \mathrm{mg} \cdot \mathrm{L}^{-1}$ are associated with lower, moderate and higher cardiovascular risks, respectively. In COPD patients, CRP levels are reported to be associated with increased cardiovascular morbidity [12]. DE TORRES et al. [2] reported no differences in CRP levels between those with cardiovascular risk factors or disease and those without them. However, this conclusion has to be interpreted very cautiously as a formal evaluation of the cardiovascular status of the patients was not included. Others have reported that CRP is a predictor of acute exacerbations of COPD [13], as well as hospital admissions and mortality in patients with chronic respiratory failure [14].

The association between asthma and CRP is by no means clear. A recent population-based study showed associations of increased levels of serum CRP with a high frequency of bronchial hyperresponsiveness [8], whereas in another multicentre epidemiological study no significant relationship could be demonstrated between bronchial hyperresponsiveness and atopy [9]. However, in the latter study, a significant relationship was found between increased CRP levels and respiratory symptoms, such as wheeze, attacks of breathlessness after effort and nocturnal cough. Furthermore, OLAFSDOTTIR et al. [9] demonstrated that nonallergic asthma in particular is strongly related to higher CRP levels, whereas allergic asthma is not. This paper also brought into focus the triad of asthma, high BMI and high CRP. In their small cross-sectional study, TAKEMURA et al. [3] have reported that the increase in serum CRP is associated with indices of pulmonary function and sputum eosinophil count, but only in the group of steroidnaïve patients. The conclusion of the authors that CRP may serve as a surrogate marker of airway inflammation in asthma at the very least needs more scientific support, particularly based on their observations that eosinophil counts were significantly increased only in the steroid-treated group. However, studies relating systemic inflammation to the level of local inflammation in COPD patients are still lacking.

In this issue of the ERJ, ANDERSON [15] discusses possible explanations for stimulated CRP production in clinically stable disease conditions. Other disease-related factors need to be evaluated, such as muscle dysfunction or neurohumoral activation [16]. DE TORRES et al. [2] stress the role of hypoxia. The profound role of hypoxia on virtually all aspects of cellular metabolism, including the hypoxic regulation of many genes involved in inflammation and other processes, is largely overlooked in respiratory medicine. Prospective studies are needed to assess the role of continuous as well as intermittent hypoxia, particularly in COPD patients. Furthermore, it will be important to study genetic determinants in order to explain increased levels of CRP. Significant associations between CRP genotypes and plasma CRP concentrations have been documented, and estimates from the National Heart, Lung, and Blood Institute Family Heart Study and twin studies from the UK and Norway indicate that heritability of serum CRP level is 40-50\% [17-21].

The studies by DE TORRES et al. [2] and TAKEMURA et al. [3] focus on the possible role of inhaled steroids in the attenuation of CRP levels in asthma and COPD. DE TORRES et al. [2] reported no differences in CRP levels between patients taking corticosteroids and those that did not. One previously published paper [22] has reported a decrease in CRP levels after treatment with inhaled corticosteroids and PINTO-PLATA et al. [6] have reported that CRP levels were lower in COPD patients treated with inhaled steroids. Most of these observational data need to be interpreted very cautiously. Well-conducted randomised trials are needed not only to demonstrate a decrease in CRP levels after intervention, but to determine a reduction in the burden of these assumed inflammationrelated complications. The notion that inhaled corticosteroids can "mend a broken heart" indeed requires better understanding of the mechanistic and epidemiological link between steroid therapy and cardiovascular disease [23]. Furthermore, cardiovascular research has clearly demonstrated that besides a variety of behavioural interventions, other pharmacological agents and particularly statins have a consistent effect on CRP levels [11], and novel anti-inflammatory therapies may become available.

However, in chronic obstructive pulmonary disease and asthma, well-conducted longitudinal studies have to be conducted now to clarify if C-reactive protein screening is helpful to enhance patient care and to reduce the burden of extrapulmonary manifestations of these diseases. At the very least, we can conclude that asthma and chronic obstructive pulmonary disease are heterogeneous complex inflammatory diseases and that low-grade systemic inflammation is probably part of the manifestations of these diseases in specific phenotypes.

\section{REFERENCES}

1 Wouters EF. Chronic obstructive pulmonary disease. 5: systemic effects of COPD. Thorax 2002; 57: 1067-1070.

2 de Torres JP, Cordoba-Lanus E, López-Aguilar C, et al. $\mathrm{C}$-reactive protein levels and clinically important predictive outcomes in stable COPD patients. Eur Respir J 2006; 27: 902-907.

3 Takemura M, Matsumoto H, Niimi A, et al. High sensitivity C-reactive protein in asthma. Eur Respir J 2006; 27: 908-912.

4 Yende S, Waterer GW, Tolley EA, et al. Inflammatory markers are associated with ventilatory limitation and muscle dysfunction in obstructive lung disease in well functioning elderly subjects. Thorax 2006; 61: 10-16.

5 Broekhuizen R, Wouters EF, Creutzberg EC, Schols AM. Raised CRP levels mark metabolic and functional impairment in advanced COPD. Thorax 2006; 61: 17-22. 
6 Pinto-Plata VM, Mullerova $\mathrm{H}$, Toso JF, et al. C-reactive protein in patients with COPD, control smokers and nonsmokers. Thorax 2006; 61: 23-28.

7 Pedersen BK, Steensberg A, Fischer C, et al. The metabolic role of IL-6 produced during exercise: is IL-6 an exercise factor? Proc Nutr Soc 2004; 63: 263-267.

8 Kony S, Zureik M, Driss F, Neukirch C, Leynaert B, Neukirch F. Association of bronchial hyperresponsiveness and lung function with C-reactive protein (CRP): a population based study. Thorax 2004; 59: 892-896.

9 Olafsdottir IS, Gislason T, Thjodleifsson B, et al. C reactive protein levels are increased in non-allergic but not allergic asthma: a multicentre epidemiological study. Thorax 2005; 60: 451-454.

10 Mannino DM, Ford ES, Redd SC. Obstructive and restrictive lung disease and markers of inflammation: data from the Third National Health and Nutrition Examination. Am J Med 2003; 114: 758-762.

11 Bassuk SS, Rifai N, Ridker PM. High-sensitivity C-reactive protein: clinical importance. Curr Probl Cardiol 2004; 29: 439-493.

12 Sin DD, Man SF. Why are patients with chronic obstructive pulmonary disease at increased risk of cardiovascular diseases? The potential role of systemic inflammation in chronic obstructive pulmonary disease. Circulation 2003; 107: 1514-1519.

13 Dev D, Wallace E, Sankaran R, et al. Value of C-reactive protein measurements in exacerbations of chronic obstructive pulmonary disease. Respir Med 1998; 92: 664-667.

14 Cano NJ, Pichard C, Roth H, et al. C-reactive protein and body mass index predict outcome in end-stage respiratory failure. Chest 2004; 126: 540-546.
15 Anderson GP. COPD, asthma and C-reactive protein. Eur Respir J 2006; 27: 874-876.

16 Andreas S, Anker SD, Scanlon PD, Somers VK. Neurohumoral activation as a link to systemic manifestations of chronic lung disease. Chest 2005; 128: 3618-3624.

17 Pankow JS, Folsom AR, Cushman M, et al. Familial and genetic determinants of systemic markers of inflammation: the NHLBI family heart study. Atherosclerosis 2001; 154: 681-689.

18 Zee RY, Ridker PM. Polymorphism in the human Creactive protein (CRP) gene, plasma concentrations of CRP, and the risk of future arterial thrombosis. Atherosclerosis 2002; 162: 217-219.

19 Szalai AJ, McCrory MA, Cooper GS, Wu J, Kimberly RP. Association between baseline levels of $\mathrm{C}$-reactive protein (CRP) and a dinucleotide repeat polymorphism in the intron of the CRP gene. Genes Immun 2002; 3: 14-19.

20 MacGregor AJ, Gallimore JR, Spector TD, Pepys MB. Genetic effects on baseline values of $\mathrm{C}$-reactive protein and serum amyloid a protein: a comparison of monozygotic and dizygotic twins. Clin Chem 2004; 50: 130-134.

21 Retterstol L, Eikvar L, Berg K. A twin study of C-reactive protein compared to other risk factors for coronary heart disease. Atherosclerosis 2003; 169: 279-282.

22 Sin DD, Man SF, McWilliams A, Lam S. Progression of airway dysplasia and C-reactive protein in smokers at high risk of lung cancer. Am J Respir Crit Care Med 2006; 173: 535-539.

23 Sin DD, Man SF. Can inhaled steroids mend a broken heart in chronic obstructive pulmonary disease? Eur Respir J 2005; 25: 589-590. 